\title{
The aircraft engines in the land vehicles
}

ARTICLE INFO

Received: 5 July 2021

Revised: 28 August 2021

Accepted: 30 August 2021

Available online: 1 September 2021
The examples of the applications of the aircraft engines to propulsion of the heavy armored land vehicles are presented in this paper. They provide the power necessary for high mobility of these land vehicles, which have a weight much greater than trucks. These engines were mass produced and thus were readily available. It was easier to repair damaged engines, too. Both spark-ignition and compression-ignition piston engines as well as turbocharged engines were used to propulsion of the armored vehicles. General solutions of the dual-purpose engines for the vehicles during the First and Second World War as well as the engines used nowadays are presented. Attention is also given to the specific solutions of these engine assemblies. Their basic technical and operational parameters are described. The implications of adapting aircraft engines to land vehicles were analyzed.

Key words: aircraft engines, land vehicles. propulsion systems, dual application, dual use

This is an open access article under the CC BY license (http://creativecommons.org/licenses/BY/4.0/)

\section{Introduction}

The application of the heavy armored vehicles featuring a weight of approximately 30 tons on the battlefields of the First World War, necessitated the use of the adequately powerful engines for their propulsion. These engines had to provide the required speed of the vehicles and the ability to overcome the terrain destroyed by the warfare. Initially, it was assumed that the speed of tanks should be close to the speed of a movement of infantry. Therefore, the first tanks introduced developed a speed up to $6 \mathrm{~km} / \mathrm{h}$ (e.g., British Mark I-IV tanks. For their propulsion one or two massproduced vehicle engines were sufficient. It quickly became apparent that a fireteam of infantry moving through the damaged terrain could not keep up with the tanks, and the vehicles themselves were destroyed or captured by the enemies. Therefore, on the one hand the works on the armored infantry carriers (the first was the British Mark IX carrier) were commenced, and on the other hand more powerful engines were searched for. Such engines should provide an increased speed of tanks making it difficult to be targeted by a projectile, and to overcome the difficult terrain. For this purpose, the aircraft engines were considered, which were adapted for a propulsion of the tanks. The development of engines for aircraft and land vehicles proceeded in parallel [10]. However, the rapid development of weaponry and warfare necessitated a partial fusion of the development paths of these engines.

The purpose of this article is to present a solution to the problem of providing the necessary number of 300-500 hp engines to power tanks and other heavy land vehicles, which developed fast in the first half of the 20th century. This was necessary to achieve the expected mobility parameters of tanks. The basic comparative indicator of such mobility was the unit power of a tank as a ratio of power to vehicle weight $(\mathrm{hp} / \mathrm{t})$. For this purpose, some aircraft engines were adopted. Solutions of such aircraft engines and their assemblies are presented, and the results of such adaptations are evaluated.
During the description of the engines presented in the photographs and the specification of their structure and operational parameters, mainly the descriptions of the presented engines were used, as they were presented on the descriptions of the tanks and engines displayed in museums. These data may differ slightly from the data from other sources.

\section{First tank engines}

The first British tanks used during the First World War (Mark I-Mark IV) were powered by the 6-cylinder Daimler - Knight engines with a displacement of $13 \mathrm{dm}^{3}$ and power of $76 \mathrm{~kW}(105 \mathrm{hp})$ at the speed of $1000 \mathrm{rpm}$ (Fig. 1). The producer of these engines was an independent British company, The Daimler Company Limited, whose founder bought the rights to use the Daimler business name from Gottlieb Daimler and an ownership title to the DaimlerMotoren-Gesellschaft. This company acquired the rights to use the sleeve valve timing mechanism in its products from Charles Knight. When this design was perfected, it produced an engine that ran quietly because it did not have many of the moving parts of a valve train system (valves, springs, pushrods). Its combustion chamber was spherical in shape, which ensured a low heat loss.

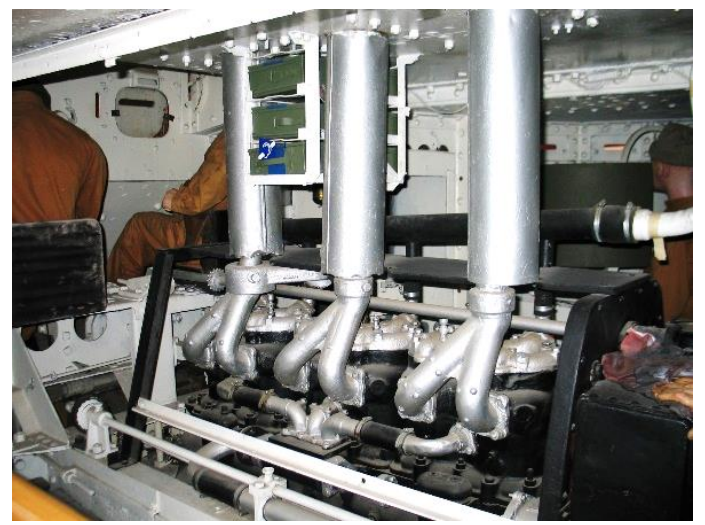

Fig. 1. The Daimler - Knight engine in the Mark II tank (The Tank Museum at Bovington Camp in Dorset, photo by the author) 
The engines from the Daimler factory caused a sensation and were mass produced by the company. These engines featured a wide power range and powered a variety of vehicles. Their popularity caused the company to discontinue the manufacturing of the overhead valve engines until the 1930s. The Daimler engines used in the first tanks were not aircraft engines, but sleeve valve timing technology also found its way into many piston aircraft engines with the inline or star cylinder positions, including the Napier highperformance engines with the H-type cylinder arrangements.

The quiet operation of the Daimler-Knight engines was their significant advantage when the engine was operated without a cover in the open interior of the tank. The crew was not exposed to the much higher noise levels that head valve engines would emit. The disadvantage of these engines constituted the unreliable lubrication systems, the unreliability of which increased as speed increased. This caused the frequent engine faults. In addition, a significant oil consumption resulted in a bluish exhaust gas color that showed the positions of the tanks powered by the engines.

The boost in engine power by increasing the combustion pressure and speed required the new engine solutions for the subsequent versions of the British tanks. This was due to the need to increase the speed of the next versions of the tanks, which weighed up to 40 tons during the First World War.

Tanks of the 38-ton Mark VIII version being the result of the British-American cooperation had a separate engine compartment with the engine in the rear part of the hull. Ricardo V-12 engines of $220 \mathrm{~kW}$ (300 HP) were used to drive the British version of the tank, while the American tanks were powered by the Liberty V-12 aircraft engines of $249 \mathrm{~kW}$ (338 hp) at $1400 \mathrm{rpm}$ (Fig. 2) [11].

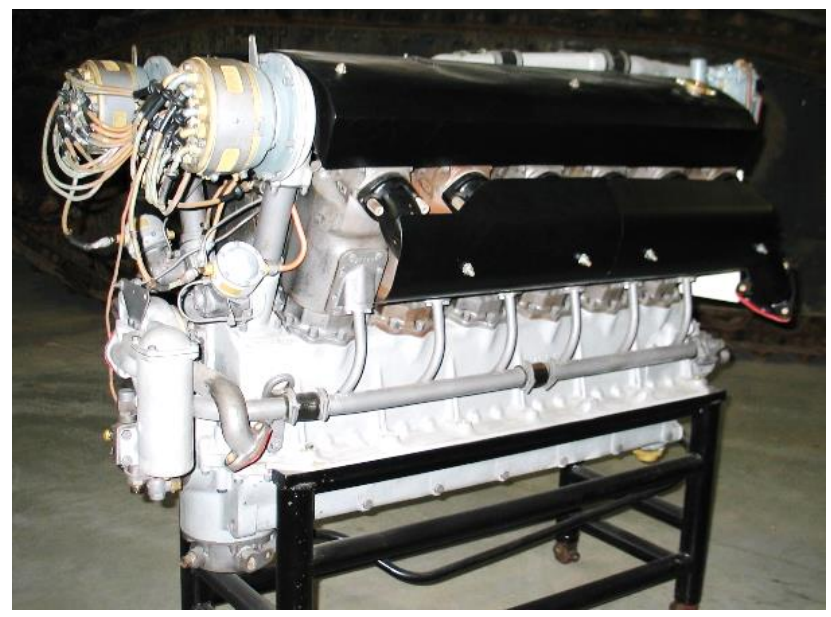

Fig. 2. The Liberty V-12 engine to power tanks (The Tank Museum at Bovington Camp in Dorset, photo by the author)

The Liberty V-12 engines were developed for the aviation [5]. They were designed so that to have a maximum power-to-weight ratio and should be easy to mass produce and service. The various versions of this engine were developed differing in the quantity and configuration of cylinders. They were 4- and 6-cylinder engines in the inline versions and from 8 up to 12 cylinders in the ' $\mathrm{V}$ ' shape versions (prototype version even had the L-8-cylinders mounted in a straight line). Later engines did not exceed 6 cylinders in a straight line. The versions of the engines with the inverted cylinders, facing downwards, supercharged versions of the engines were also developed. The largest engine was the X-24 (24 cylinders in the ' $\mathrm{X}$ ' layout), 12 of which were in two rows facing up and 12 cylinders facing down.

The Liberty engine was designed in a record short time of less than two months. It had single steel cylinders bolted to an aluminum crankcase. The cylinders were expanded at the top to allow for larger valve diameters (Fig. 3). The jackets of the liquid cooling system were welded to the cylinders. Individual camshafts for each row of valves were rotated by means of king shafts and bevel gears. Ignition distributors were mounted on the ends of the shafts. The design of the cylinders and camshaft drive was based on the Mercedes Benz D.III engine for the German aircraft, as well as the solutions of other aircraft engines.

The cylinders of the Liberty engine were forked at the angle of $45^{\circ}$. The V-12 twelve-cylinder engine had a capacity of $27 \mathrm{dm}^{3}$, the ratio of stroke to piston diameter was of $1.4(\mathrm{~S} / \mathrm{D}=178 \times 127 \mathrm{~mm})$, and its compression ratio was $\varepsilon=$ $=5.4$; compression ratio of the engine was lowered in the non-aircraft versions. In the tank version, the output of the Liberty engine was of $250 \mathrm{~kW}$ (340 hp) at $1400 \mathrm{rpm}$ [11].

A major advantage of the Liberty engines constituted their modularity, that enabled to create the engines with the different numbers of cylinders and their configuration. The engine also had design flaws that were partially corrected, however vibration during engine operation was not completely eliminated. Its durability was not high.

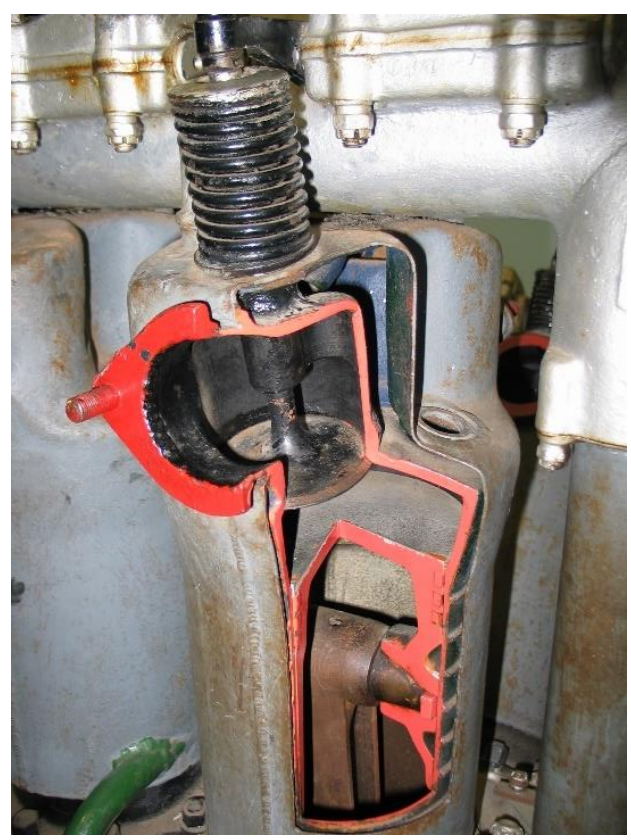

Fig. 3. Combustion chamber of the Liberty V-12 engine (The Tank Museum at Bovington Camp in Dorset, photo by the author)

\section{The engines from the period of the Second World War}

The rights to produce the Liberty $\mathrm{V}-12$ engines were acquired by the British before the Second World War. They planned to use these engines to power the fast Cruiser MK III and MK IV tanks and their subsequent versions (Cru- 
sader, Cavalier and Centaur). These engines developed 250 $\mathrm{kW}$ (340 hp) running at $1500 \mathrm{rpm}$. This was not sufficient to drive next generations of tanks featuring the increasing weight and to provide them with a sufficiently high ratio of power to vehicle weight. It was necessary to search for the more powerful engines. In the beginning, the power of Nuffield Liberty engines produced in Great Britain was increased. Despite obtaining $310 \mathrm{~kW}(410 \mathrm{hp})$, the assumed unit power of tanks of $20 \mathrm{hp} / \mathrm{ton}(15 \mathrm{~kW} / \mathrm{t})$ was not achieved. Therefore, it was decided to adapt the Rolls-Royce aircraft engines to power the tanks.

Initially, the use of the Rolls-Royce Kestrel engines was considered, but they did not provide the required unit power and larger engines were necessary. The Rolls-Royce Merlin met these requirements. In the aircraft version, these were engines in a V-12-cylinder configuration with supercharging by mechanically driven compressors (Fig. 4). These engines were commonly used to power the British fighter and bomber aircraft. Their adaptation to the tank propulsion was not difficult, although many significant changes had to be made. This primarily involved removing the air compressors and their transmission systems, building liquid cooling systems for the engines with air fans, making changes to the lubrication and fuel supply systems, and making the auxiliary engine units drive from the camshafts on each head. In the land version, the engines were fueled with low-octane gasoline instead of high-octane jet fuel.

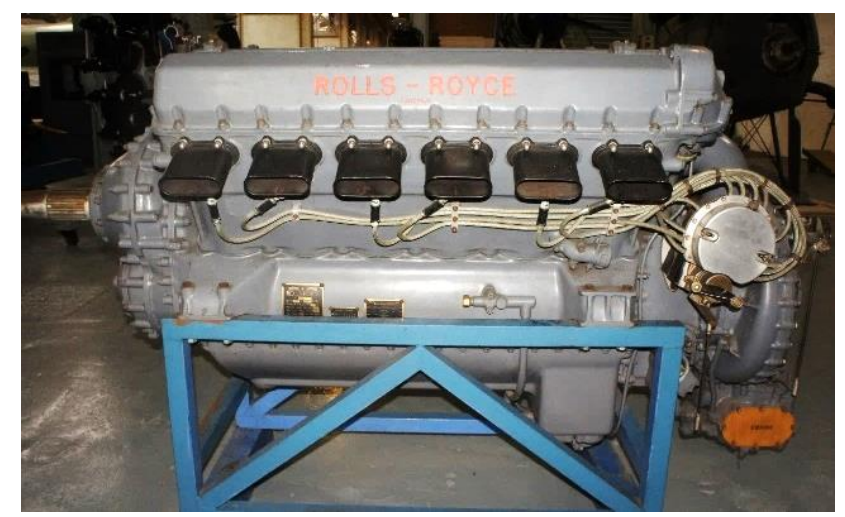

Fig. 4. The Rolls-Royce Merlin engine with centrifugal compressor (Royal Museum of Army and Military History, Brussels, photos by the author)

The land version of the engines, known as the R-R Meteor, had a power output of $450 \mathrm{~kW}(600 \mathrm{hp})$ at $2500 \mathrm{rpm}$ (Fig. 5) [6]. The piston stroke was equal to $150 \mathrm{~mm}$, the cylinder diameter was of $140 \mathrm{~mm}$, and the compression ratio depended on the version (from $\varepsilon=6: 1$ to $\varepsilon=7: 1$ ). The use of these engines to drive the 28-ton Cromwell tanks (A27T Cruiser Tank) provided the specific tank power at the required level of $21.4 \mathrm{hp} / \mathrm{t}(16 \mathrm{~kW} / \mathrm{t})$ and cruising speeds up to $64 \mathrm{~km} / \mathrm{h}$ tanks and engines.

These engines powered many post-war British tanks, which were originally the upgraded versions of the Cromwell tank such as the Comet A34 (weight of $33 \mathrm{t}$ ) and the Challenger A30 (weight of $32 \mathrm{t}$ ). They were also used to propel the later tanks with much higher weight which resulted in reduction of their speed. For example, the Centurion tank had a weight of 52 ton and its maximum speed was of $35 \mathrm{~km} / \mathrm{h}$, while the experimental Tortoise tank with a weight of 79 ton had a speed of only $20 \mathrm{~km} / \mathrm{h}$.

The Rolls-Royce Meteor M120 gasoline-injected engines were developed to power the 64-ton Conqueror (FV 214) heavy tanks. These engines developed $810 \mathrm{hp} \mathrm{(640}$ $\mathrm{kW}$ ) and provided the tank with a cruising speed of up to 35 $\mathrm{km} / \mathrm{h}$. A smaller version of this engine designated as the Rolls-Royce Meteorite was also developed with a V8 cylinder configuration and a displacement of approx. $18 \mathrm{dm}^{3}$. They were used to power wheeled tractors, small ships, and stationary equipment. The power output of these engines was of $190 \mathrm{~kW}(260 \mathrm{hp})$ at $2300 \mathrm{rpm}$ in the Mk. 204 version, and in the Mk. 202B version the engine developed $380 \mathrm{~kW}(520 \mathrm{hp})$ at $2700 \mathrm{rpm}$.

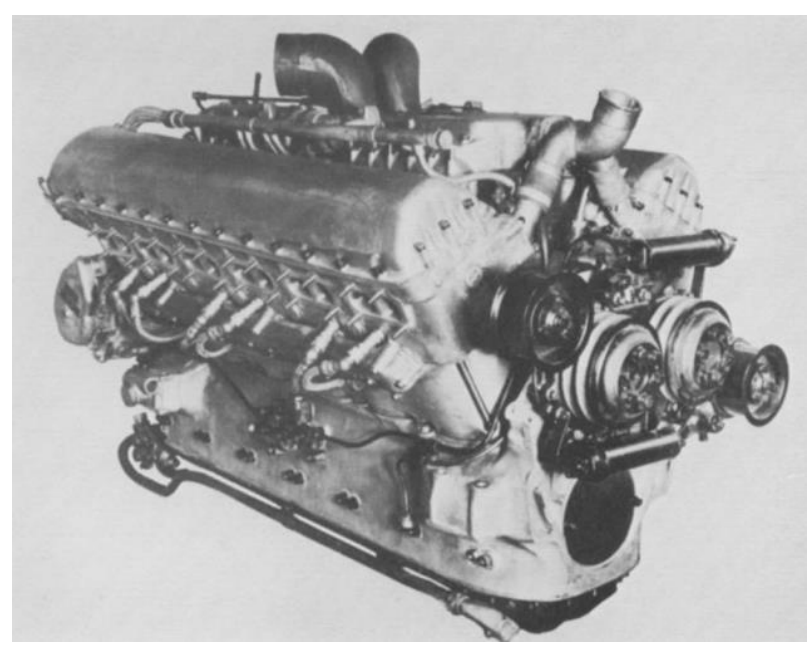

Fig. 5. The Rolls-Royce Meteor engine without any compressor [6]

The aircraft engines were commonly used to power the American light and medium tanks and many other tracked (floating) vehicles within a period of the Second World War. The Continental R-670 engines (factory designation W-670) were used to power the M1, M2 and M3 light tanks and the different varieties of the LVT (Landing Vehicles Tracked) tracked amphibious vehicles used in landing operations. They were 7-cylinder engines of about $180 \mathrm{~kW}$ (250 hp) at $2400 \mathrm{rpm}$, with a star cylinder arrangement of a capacity of circa $11 \mathrm{dm}^{3}$ (piston stroke of $117.5 \mathrm{~mm}$, cylinder diameter of $130.2 \mathrm{~mm}$ ) and a weight of circa 200 $\mathrm{kg}$ [11]. The engines were air-cooled, which required a suitably large blower and covers directing the airflow to the cylinder ribs and head (Figure 6). They were fueled with low-octane gasoline via a carburetor. The fuel-injected versions of the engine with an increased compression ratio and a power up to $6 \%$ were also developed. Unlike the aircraft engines, these engines had the flywheels to help start the vehicle and the cooling air blowers.

Some of the M3 light tanks (M3-Diesel) were powered by the Guilberson T-1020-4 9-cylinder, star compressionignition aircraft engines of circa $180 \mathrm{~kW}(250 \mathrm{hp})$ at 2200 $\mathrm{rpm}$. These engines, with a displacement of $16.7 \mathrm{dm}^{3}$ (piston stroke of $140 \mathrm{~mm}$, cylinder diameter of $130 \mathrm{~mm}$ ), had a compression ratio equal to $\varepsilon=15$, a weight of circa 300 $\mathrm{kg}$ and were air-cooled [5]. 
The larger armored vehicles required more powerful engines. The mass-produced Wright R-975 Whirlwind engines were used for this purpose. They were developed and produced by a division of the Curtiss-Wright, but most of these engines were built under a license by the Continental Motors Company. These engines were chosen initially to power the M2 tank, weighing approximately 18 tons, and later for the heavier M3 Lee and M4 Sherman tanks. They were also used to power the M7 self-propelled guns, tank destroyers and many other specialized vehicles built on the same chassis as the M3 and M4 tanks.

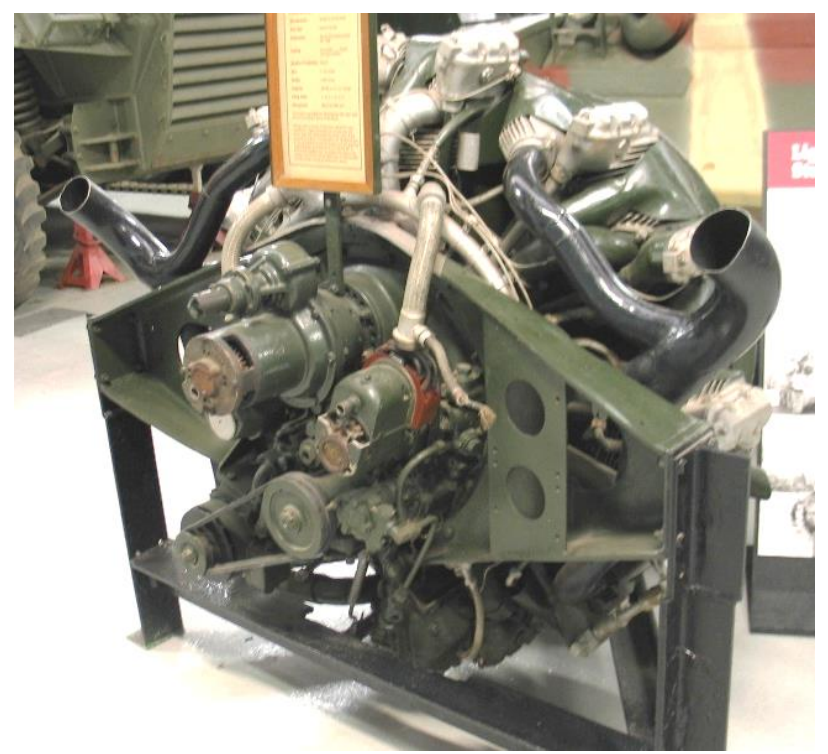

Fig. 6. The Continental W670-9A engine (The Tank Museum at Bovington Camp in Dorset, photo by the author)

The R-975 engines were 9-cylinder spark-ignited star engines (Fig. 7). They were air-cooled by a blower located on the torque take-off shaft. The engines had a displacement of circa $16 \mathrm{dm}^{3}$ (piston stroke of $140 \mathrm{~mm}$ and cylinder diameter of $127 \mathrm{~mm}$ ) with a power rating of 220-340 kW (300-450 hp), depending on the engine version [11]. The increase in power of the subsequent versions of the engine was achieved through design changes in the engine head, increasing its compression ratio and the maximum speed and supercharging the air. After the war, the Continental developed this engine by increasing its starting power to about $390 \mathrm{~kW}(530 \mathrm{hp})$ at $2300 \mathrm{rpm}$.

The M4 Sherman tanks were powered by a variety of engines, including aircraft engines, featuring $266-330 \mathrm{~kW}$ (350-450 hp), which gave the tanks a unit power of $11-$ $13.5 \mathrm{hp} / \mathrm{t}$ and provided a cruising speed of $35-48 \mathrm{~km} / \mathrm{h}$. A large number of the versions of the tanks and vehicles on their chassis, as well as engines for these vehicles, makes their exact specification difficult. Their parameters vary depending on the source and therefore approximate values are given. For the propulsion of the mass-market versions of the Sherman M4 and M4A1 tanks, the versions of the R-975 engine with $260-300 \mathrm{~kW}(350-400 \mathrm{hp})$ at $2400 \mathrm{rpm}$ were used.

The final production version of the Sherman tank was the M4A6 tank. It was powered by a modified version of the Wright R-1820 Cyclone 9-cylinder aircraft gasoline engine, adapted for self-ignition and diesel fuel supply by the Caterpillar Inc. The Caterpillar used the crankshaft, crankcase, cylinders, and supercharging system of the R-1820 gasoline engine for its project (Fig. 8). This new engine was designated the RD-1820. This supercharged engine had a weight of circa $0.8 \mathrm{t}$; displacement of circa $29.9 \mathrm{dm}^{3}$; piston stroke to cylinder diameter ratio $\mathrm{S} / \mathrm{D}=$ $=1.12$ (stroke of $174.6 \mathrm{~mm}$, diameter of $155.6 \mathrm{~mm})$; compression ratio $\varepsilon=15.5$ and developed power of $330 \mathrm{~kW}$ (450 hp) at a speed of $2000 \mathrm{rpm}$. Maximum speed was limited by a speed controller. The M4A6 tank developed a maximum speed of close to $50 \mathrm{~km} / \mathrm{h}(31 \mathrm{mph})$ and had good multi-fuel capability - it could run on both diesel fuel and low-octane gasoline.

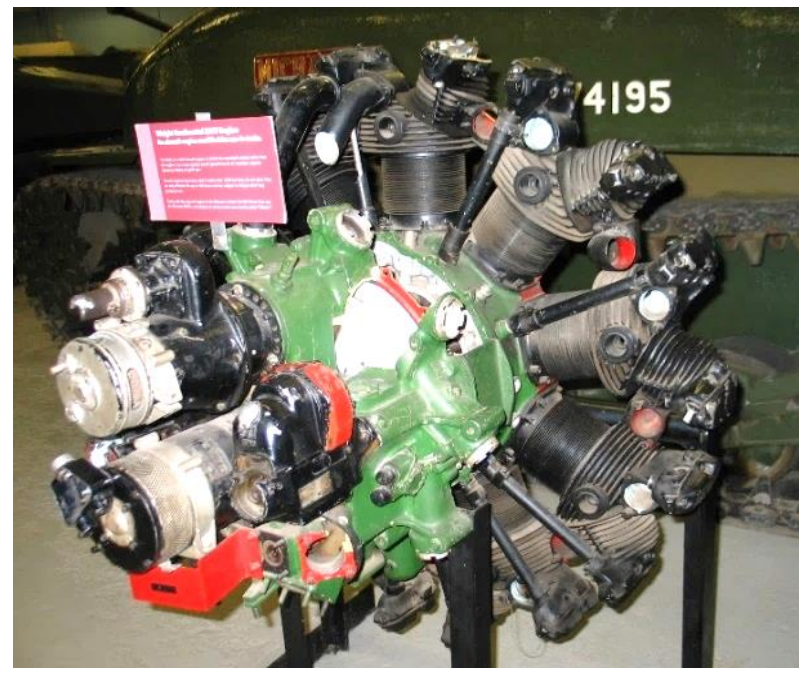

Fig. 7. Wright R-975 engine (The Tank Museum at Bovington Camp in Dorset, photo by the author)

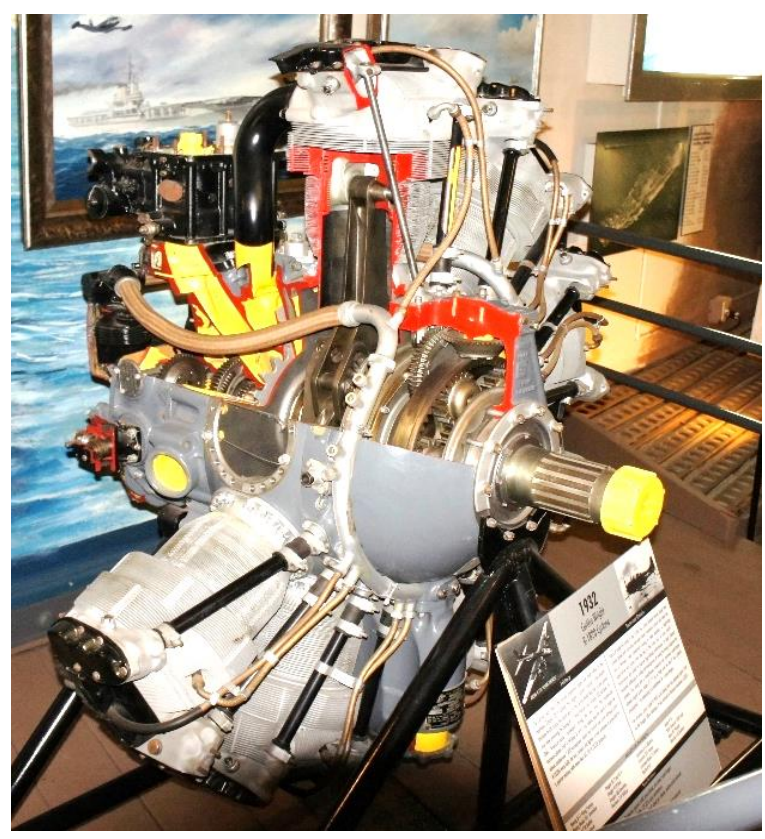

Fig. 8. Cross-section of the Cyclone Wright R-1820 engine (San Diego Air and Space Museum, photo by the author)

The Wright R-1820 G-200 gasoline engine with power increased to $660 \mathrm{~kW}(900 \mathrm{hp}$ ) at $2300 \mathrm{rpm}$ was used to 
power the experimental M6 heavy tank with a combat weight of 57.4 ton and a maximum speed of $35 \mathrm{~km} / \mathrm{h}$.

Another American aircraft engine used to power many types of tanks were the Ford GAA inline cylinder configuration engines (Fig. 9). These engines were used to power the M4A3 Sherman tanks and their upgraded chassis version, and later many other tanks, including the M26 Patton medium tank in the different $42 \mathrm{t}$ variants (Ford GAF engine version).

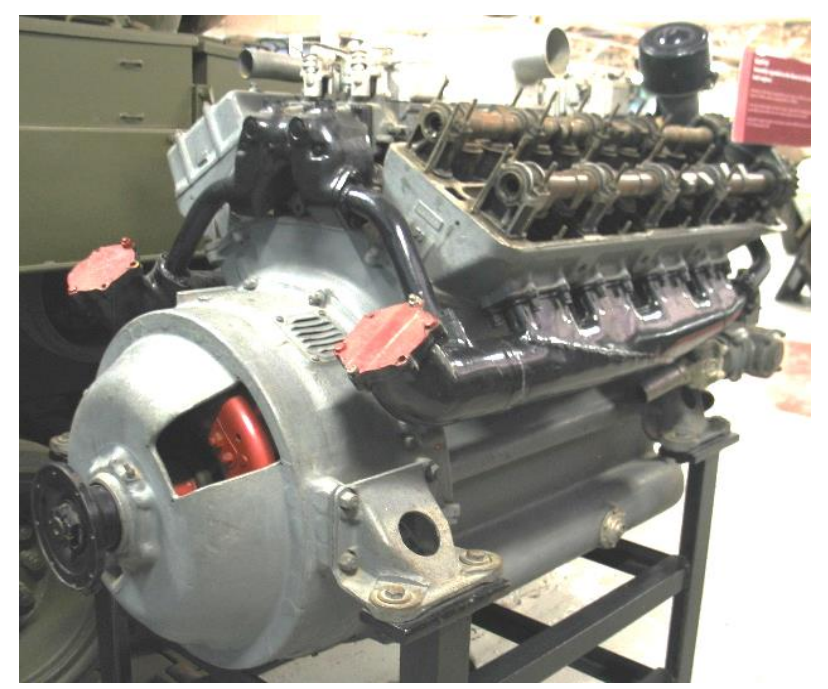

Fig. 9. The Wright Ford GAA engine (The Tank Museum at Bovington Camp in Dorset, photo by the author)

The Ford GAA engines were originally designed as naturally aspirated V-12-cylinder aircraft engines with aluminum cylinder blocks, crankcases, and heads [7]. They were engines with the same piston-crank system dimensions and $60^{\circ}$ cylinder row pitch as the RR-Merlin engines. They had two camshafts in the head and were liquid cooled. They did not find acceptance as aircraft engines. Since there was a shortage of engines to power the M4 Sherman tanks it was decided to produce these engines, but in a V-8-cylinder version. These engines had a power output of $373 \mathrm{~kW}$ (500 $\mathrm{hp)}$ at $2600 \mathrm{rpm}$, sufficient to drive the M4 tank. In this version the Ford GAA engine had a displacement of 18 $\mathrm{dm}^{3}$, compression ratio of $\varepsilon=7.5$; piston stroke of $15.2 \mathrm{~cm}$, cylinder diameter of $13.7 \mathrm{~cm}$ and two carburetors, one for each row of cylinders [11]. The GAA version of the engine differed from the GAF version in the type of Stromberg carburetors.

After the war, the twelve-cylinder engines were revised in the Ford GAC version with power increased to $480 \mathrm{~kW}$ (650 hp) at a speed $2800 \mathrm{rpm}$. They were used to power the prototype T29 heavy tanks (weight of $64 \mathrm{t}$ ) and T32 tanks (weight of $54 \mathrm{t}$ ).

In the further versions of tanks produced in a large quantity, air-cooled engines in the V-12-cylinder configuration and with a displacement of $29.3 \mathrm{dm}^{3}$ (1790 in. ${ }^{3}$ ) were developed. These were spark-ignition V-12 engines: Continental AV-1790 (tanks: M-46, M-47, and M-48) and selfignition Continental AVDS-1790 (tanks M-60, Merkava, Centurion). In some versions of the engines turbocharging was used.
The T23 tank was one of the tanks powered by the Ford GAN aircraft engine. It was built as a replacement intended for the M4 Sherman tank. It had an electric transmission system. The Ford GAN engine drove an electric generator (Fig. 10). The generator powered two drive motors with reducers that drove the drive wheels of the tank (Fig. 11). This electrical connection between the engine and the wheels allowed the engine to maintain operation as close to the optimum conditions as possible. The tank with this drive system could change direction with any steering angle (stepless). The vehicle could be controlled from any place inside and outside the tank at a distance limited by the length of the cable. The chassis of the tank was adapted from the M4 Sherman tank.

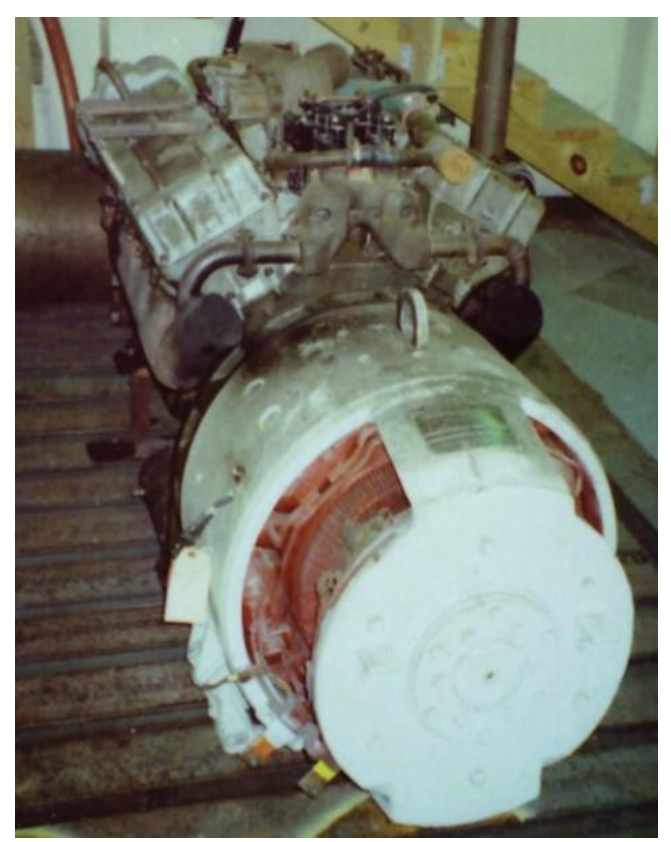

Fig. 10. The Ford GAA engine driving the alternator (photo by the author)

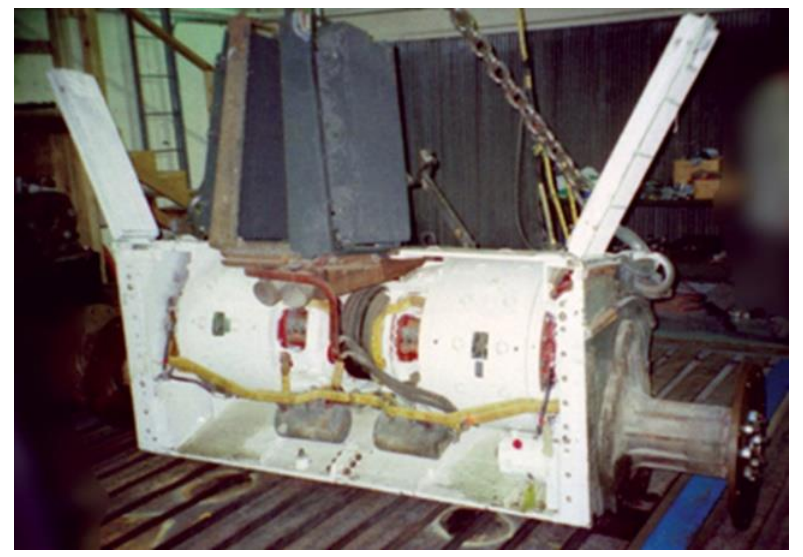

Fig. 11. The T-23 tank propulsion electric motors and reductors (photo by author)

Despite the good road and terrain properties of the tank equipped with electric and diesel propulsion, such a propulsion system was eventually abandoned. This was due to the necessity of providing well-trained and equipped operating facilities. 
The history of the W-2 engines, which were developed as engines for driving land vehicles: tanks, self-propelled guns, and artillery tractors, was different. Like the aircraft engines, they had crankcases, cylinder blocks, pistons and heads made of aluminum alloys. They were self-ignition engines. Developed in the 1930 s by a team with no experience in engine design. The work of this team was assisted by the experienced engine designers from other aircraft institutes, so they are in the structural terms like the aforementioned engines. One of the most important experts was A. D. Charomskij, in whose team the diesel aircraft engines ACh-30 and ACh-40 were developed based on the experimental engine AN-1 [5]. The W-2 engine had the same configuration of cylinders and similar design solutions to Charomskij's engines, but it had smaller piston and cylinder dimensions and thus a smaller displacement (Fig. 12).

The structure of the W-2 engines like the aircraft engines was also influenced by the development of the aircraft engine production in the USSR in the 1920s and 1930s. For this production, machine tools and tooling were purchased in the West and in the USA, as well as patents, technologies, and licenses for the aircraft engine production.

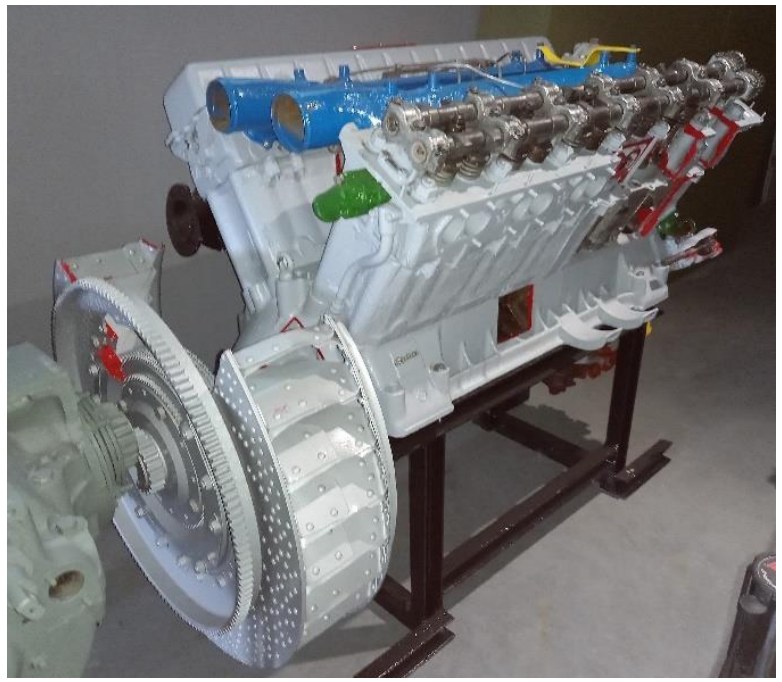

Fig. 12. The W-2 engine (Armored Weaponry Museum, Poznan, photo by the author)

The W-2 engines were first supplied with the fuel injection equipment produced by the German company Bosch (feed pumps, injection pumps and injectors). After the production of these units was developed locally, they were applied to the engines produced in the various production plants within the territory of the USSR.

The W-2 engines were of the V-type 12-cylinder engines with a $60^{\circ}$-cylinder row pitch angle, with a single connecting rod [1]. The basic version of the engine had a power output of $368 \mathrm{~kW}(500 \mathrm{hp})$ at a speed of $1800 \mathrm{rpm}$. Reduced- and increased-power versions of the engines were also developed. Upon the use of a mechanically driven centrifugal compressor from the AM-38 aircraft engine, the power of the W-2 (W-12SN) engine was increased to 625 $\mathrm{kW}(850 \mathrm{hp})$. The straight six-cylinder W-6 engines with a power of $180 \mathrm{~kW}(240 \mathrm{hp})$ were also developed [1].
The cylinder diameter of the W-2 engines was of $150 \mathrm{~mm}$, and their piston stroke depended on the connecting rod. The piston stroke of the main connecting rods was of $180 \mathrm{~mm}$ and that of the connecting rods was of 186.7 $\mathrm{mm}$. This resulted in a little variation in the compression ratios of the cylinder rows. The dry weight of the engine was of $750 \mathrm{~kg}$. The cylinder heads and blocks were attached to the crankcase by the long tie bolts. The crankcase was split into the main bearing axis and the parts were bolted together (Fig. 13). Starting could be done with an electric starter or compressed air. The engine was produced under license in many countries.

There are mentions of a project to develop a version of the W-2A engine for a reconnaissance aircraft which would provide a significant increase in operational range. However, the aircraft turned out to be obsolete in comparison with other pre-war aircrafts, and furthermore, the refinement of the engine version to the requirements of its use in the aircraft would have been laborious. Therefore, this idea was abandoned.

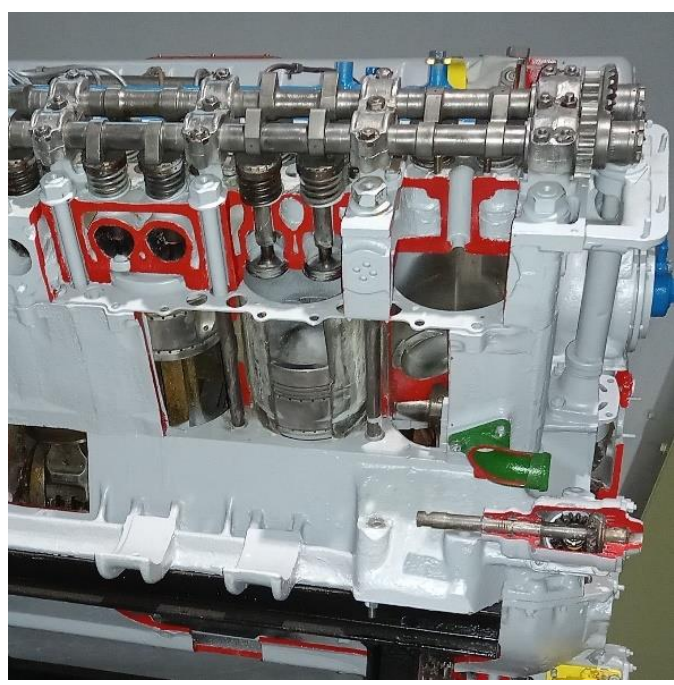

Fig. 13. The W-2 engine, cross-section (Armored Weaponry Museum, Poznan, photo by the author)

\section{Present engines}

The only mass-produced post-war engine that was developed using aircraft engine assemblies was the AGT1500 engine. This engine was chosen to power the US M1Abrams tank, introduced into service in 1976 [7]. These engines were selected during the project on the MBT-70 medium tank because of the choice between the AGT-1500 turboshaft engine and the AVCR-1360 variable compression ratio piston engine (these were the rebuilt Continental AVDS-1790 engines).

While designing the AGT-1500 engine, the AVCO Lycoming drew on its own experience in producing turboshaft engines for the helicopters and the PLT27 turbine engine solution. This was a $2000 \mathrm{hp}(1470 \mathrm{~kW})$ engine in which the low-pressure part consisted of a five-stage axial compressor connected and powered by a shaft to the lowpressure turbine [9].

The high compression part included a four-stage axial compressor and a single stage radial compressor connected by a shaft to a single stage turbine [8]. Both parts of the 
engine operated independently, and their speed depends only on the aero- and thermodynamic relationships between the compressors and turbines. Behind the turbines driving the compressors were two stages of drive turbines and a planetary reducer. This is where a similarity between the two engines ends. The annular single combustion chamber of the PLT27 engine with a return flow was replaced in the AGT-1500 engines by a single tubular combustion chamber on the side of the engine and a helical exhaust flow channel to the diesel turbine blades (Fig. 14). A heat recuperator was placed in place of the annular combustion chamber, where air compressed to $1.3 \mathrm{MPa}$ for an engine power of $1500 \mathrm{hp}(1100 \mathrm{~kW})$ was preheated with exhaust gas downstream of the drive turbines. The heat recuperation reduced the fuel consumption of this engine. The compressed air pressure depends on the engine power, and it is decreased to $0.254 \mathrm{MPa}$ for idling $\left(\mathrm{N}_{\mathrm{e}}=40 \mathrm{hp}, 30 \mathrm{~kW}\right)$ [2]. The various versions of the AGT-1500 engines were developed with the improved operating parameters and increased operating economy.

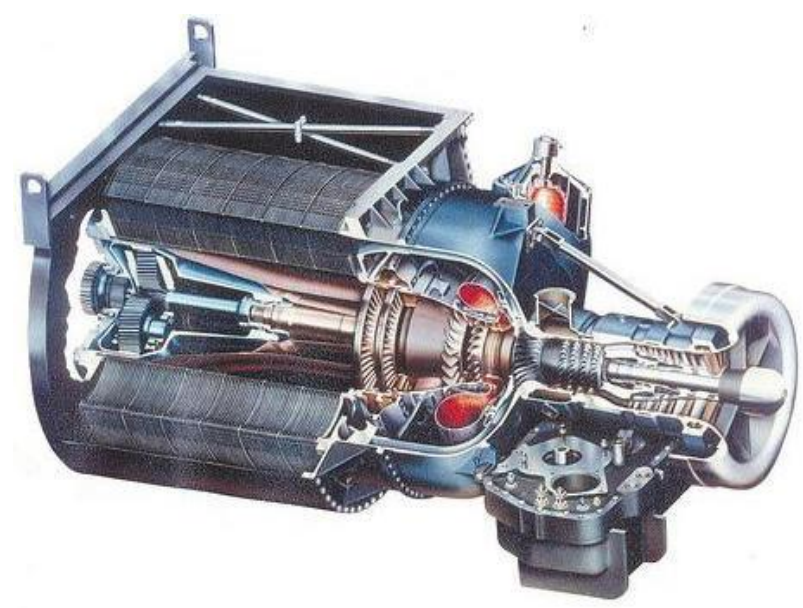

Fig. 14. The AGT-1500 engine (source: M1Abrams tank description, Internet)

\section{Summary}

The need for the 300-500 hp (220-370 kW) engines to power the heavy armored vehicles was addressed in the different ways by the countries participating in the Second World War. The Western Allies used the gasoline-powered aircraft engines with star and inline/straight line arrangements of the cylinders for this purpose. The Soviet Union used the diesel-powered engines in their tanks and heavy tractors, which were developed to power the land vehicles, but their solutions were the same as in the aircraft engines. Their opponents, the Germans produced the high-powered engines designed only to power the land vehicles. These were the spark-ignition engines that ran on gasoline with a high proportion of synthetic gasoline.

Considering the scale of applications of aircraft engines for tank propulsion, it is necessary to assess the consequences of the four most important decisions taken to application:

1. Gasoline-powered star aircraft engines for American light tanks M3/M5 Stuart and M4 Sherman

2. RR-Merlin (Meteor) and Ford GAA in-line petrol engines for British and American tanks
3. W-2 diesel engine for Soviet tanks

4. AGT-1500 turboshaft engine for US M1 Abrams tanks.

The mass use of the air-cooled aircraft radial engines to power tanks made it easy to produce large numbers of these engines at low cost. However, it was not advantageous in the practical terms and resulted in heavy tank losses. The drive shaft from the radial engine led under the tank turret increased its height and made it easier to hit with the projectiles. The exhaust system from the star engine was very elaborate inside the engine compartment. This facilitated the tank ignition upon its hitting by a shell, even if it did not penetrate the armor. The strong shock of a hit tank could easily unseal the fuel system and cause the fuel to leak and then ignite. The development of fire was favored by the intense, turbulent flow of cooling air in the engine compartment. It was estimated that $60-90 \%$ of the losses of tanks powered by star aircraft engines were as a consequence of their burning, and popular names for these tanks were "Ronson burner" (Allied term) or "Tommy Cooker" (German term) [3].

The more successful adaptations of aircraft engines to power tanks were the use V-60-engines (two banks of cylinder and one crankshaft, $\mathrm{V}$-angle of $60^{\circ}$ ). RR-Meteor and Ford GAA engines developed for aircraft were used to power some British and American tanks. Despite being supplied with petrol, they were not as susceptible to fire as star engines. The RR-Meteor engine was developed, increased its power, and used to propulsion several British post-war tanks. Also, the Ford GAA engine was used in several tanks developed in production after the war, until the development of a tank-only engine (AV-1790) [7].

Diesel engines were less prone to fire. These were mainly Soviet Union engines based on the W-2 engine design. Compression-ignition engines were Japanese tank engines (e.g. Type 97 Chi-Ha with a Mitsubishi $125 \mathrm{~kW}$ engine, Type 1 Chi-He with a Mitsubishi $177 \mathrm{~kW}$ engine) and some American tank engines. Before the war, diesel engines were also used in Polish tanks (7TP tanks with PZInż. 235 engine). The use of such fuel resulted in the high requirements in respect of the fuel quality and cleanliness, as well as maintenance of these engines. However, more important was their greater resistance to fire.

Self-ignition of the mixture also has several other advantages. The diesel engines can also be fueled with aircraft kerosene and, under the special circumstances, even briefly with low-octane gasoline. The engines have no ignition system that can interfere with the communications equipment. More heat can be obtained from a comparable volume of diesel fuel compared to gasoline, making the engines more economical. The disadvantage of such a power system is a sensitivity of diesel fuel to low temperatures and the possibility of fuel filter blockage at such temperatures. This generally requires engine start-up heaters.

The tank engines originated from the aircraft engines were mostly made of aluminum alloys. These are less resistant to mechanical impact and temperature than cast iron. The use of lightweight materials reduced the weight of the engines, which undoubtedly made them easier to replace. During the warfare, this constituted an important advantage, as a rapid replacement of the entire assemblies is the prima- 
ry means of recovering the damaged vehicles. A significant disadvantage of the "aluminum" engines is the lower rigidity of such cylinder blocks and crankcases, which can impair their durability under large and frequent changes in engine load. This is a typical load on land vehicle engines.

The W-2 engines with these properties and design solutions were a very successful design based on the forwardlooking concept of an universal engine power about $500 \mathrm{hp}$ $(368 \mathrm{~kW})$. In subsequent years they were upgraded to increase their power output. In the contemporary W-99 version with two turbochargers, $1200 \mathrm{hp}(883 \mathrm{~kW})$ was achieved [7]. The breakthrough idea was the transverse arrangement of this engine in the T-55 tank, which signifi- cantly shortened its length and reduced the weight of the tank.

The turbine engines have better traction characteristics than the piston ones (multi-fuel, maximum turbine drive torque when starting and no torque discontinuity at the low speed). However, the operational and maintenance problems and the higher fuel consumption are greater in unsteady states. There is no indication that these engines will be developed to power heavy vehicles, including tanks. The improved LV-100 turbine engine was developed for this tank [4]. However, there is no indication of its implementation. Gas turbines could be used to drive electricity generators in hybrid drives if this is cost-effective.

\section{Nomenclature}

D cylinder diameter

$\mathrm{N}_{\mathrm{e}} \quad$ engine power

$\mathrm{S}$ piston stroke
$\mathrm{V}_{\mathrm{s}} \quad$ cylinder didplacement

$\varepsilon \quad$ compression ratio

\section{Bibliography}

[1] BELOV, P. et al. Engines of Army Vehicles. USSR Ministry of Defence Publishing House. Moscow 1972 (Russian edition).

[2] DODGE, L.G. et al. Fouling tests of AGT-1500 gas turbine fuel nozzle, interim report BFLRF No. 258, AD-A203 360. Belvoir Fuels and Lubricants Research Facility (SwRI). San Antonio, Texas 78284, Sept. 1988.

[3] FOX, J. The wrong truck: the inferiority of American tanks in WW II. Southern Virginia University, 10 May 2010.

[4] FINN, D.P., The Abrams-Crusader Common Engine. ARMOR. March-April 2002.

[5] GUNSTON, B. World Encyclopedia of Aero Engines, V Edition, Sutton Publishing Limited, Bill Gunston. 2006.

[6] LLOYD, I., Rolls-Royce. The Merlin at War, Palgrave Macmillan. UK 1978.

https://doi.org/10.1007/978-1-349-03908-1

[7] OGORKIEWICZ, R. Tanks: 100 Years of Evolution, Bloomsbury Publishing PLC. 2015.

[8] POPOV, N.S. (ed.). Transport vehicles with gas turbine engines. Mashinostroenie. Leningrad 1987 (Russian edition).

[9] RUBINS, P.L. et al. PLT 27 gas turbine engine exhaust emission and noise measurements. Avco Lycoming Division Report AD/A-001 728, Stratford. Connecticut 06497, September 1974.

[10] WALENTYNOWICZ, J., History of heat engine development. Publications of the Institute of Aviation. Warsaw 2011 (Polish edition), ISBN 978-83-932592-4-3.

[11] Descriptions of engines and tanks exhibited in museums.
Prof. Jerzy Walentynowicz, DSc. DEng. - Faculty of Mechanical Engineering, Military University of Technology, Warsaw.

e-mail: jerzy.walentynowicz@wat.edu.pl 